\title{
La "realidad irreal" de la documentación gráfica histórica
}

\author{
Juan Carlos Hernández Núñez \\ Centro de Documentación del IAAP
}

"Una imagen vale más que mil palabras". No hace falta explicar que significa este dicho popular que estamos tan acostumbrados a escuchar y que inmediatamente, por nuestro modo de vida, lo ponemos en relación con la televisión, el cine o la fotografía. Es cierto

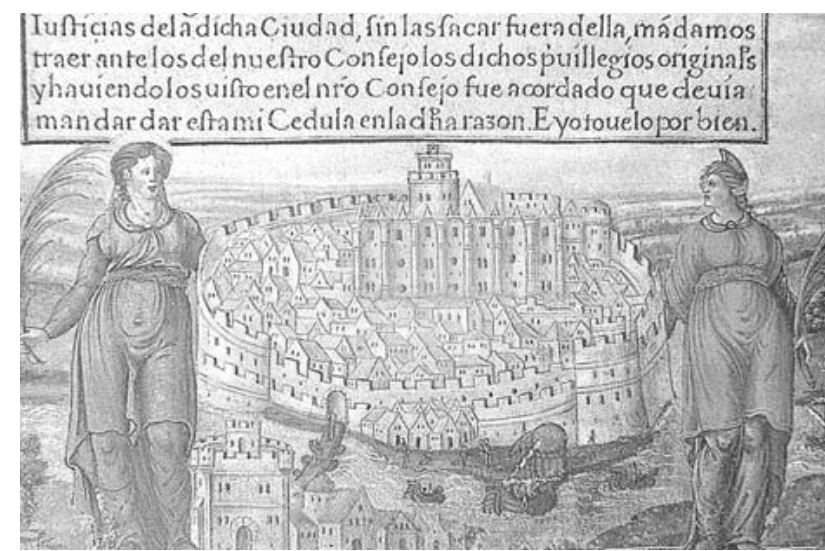

Cédula de Carlos V de 16 de julio de I549. Detalle. objeto, por muy exhaustiva que sea, nunca reflejará la realidad tan fielmente como la imagen que se puede tener del mismo. Es por esta razón, por lo que la fotografía, se ha convertido en un elemento habitual en cualquier publicación. Su capacidad para captar fielmente la realidad, la han convertido en el principal elemento de apoyo de trabajos científicos, resultando especialmente útil en las tareas relativas a la tutela del Patrimonio Histórico o Cultural. Por otra parte, se trata de una técnica, cuyos resultados son perfectamente valorables y comprensibles incluso por los no especialistas. Sin embargo, existe otro tipo de documentación gráfica de carácter histórico, que en muchos casos no resulta tan fácilmente entendible y que puede incluso representar desvirtuada la realidad. Es el caso de la documentación gráfica integrada por planos, dibujos, grabados, pinturas, relieves o maquetas, realizadas a lo largo de la historia y hasta el siglo XIX. Dicha documentación puede ser tan valiosa como actualmente lo es la fotografía, especialmente, si se tiene en cuenta que hasta el invento de ésta, dichas técnicas eran las únicas que podían sustituir a la realidad mediante su representación figurativa. A pesar de ello, estas representaciones se encuentran condicionadas por la finalidad con las que fueron realizadas por sus autores, estando también mediatizadas por la cultura de su época. Así, en ocasiones, ofrecen una "realidad irreal" que puede llevar aparejada una mala interpretación de la misma, y que puede condicionar decisivamente el trabajo de investigación realizado partiendo de ellas. Por esta razón dicha documentación se ha de completar con otro tipo de documentación, como la textual o bibliográfica, que puede facilitar una más correcta y precisa interpretación de las imágenes.

Esta reflexión de carácter general, puede encontrar su concreción en una ciudad como Sevilla, que siempre sedujo a sus visitantes y despertó el interés por representarla a numerosos artistas de distintas épocas. Así, analizando la documentación gráfica que sobre la ciudad ha llegado hasta nuestros días, se descubriría que muchas de ellas muestran una visión falsa de la misma, tanto en su conjunto como en la individualidad de sus monumentos y que incluso esa visión se ha mantenido en algunos países europeos hasta el siglo pasado en el que fueron rebatidas o aclaradas, una vez que las fotografías comenzaron a circular más allá de las fronteras hispanas. No obstante, en el conjunto de la documentación gráfica relativa a Sevilla hay un considerable "corpus" de imágenes cuya finalidad las situaría en el punto contrario del tema de la "realidad irreal" que se pretende aqui desarrollar. Se trata del conjunto de elementos gráficos integrado por planos de edificios aislados o de sectores de la ciudad, cuyos fines son constructivos, urbanísticos, defensivos, etc. Debido a estos objetivos y a su carácter práctico, la ciudad o sus edificios se encuentran perfectamente definidos y fielmente representados, estando, en muchas ocasiones, incluso reproducidos a escala y convenientemente acotados. Por otro lado, dichas representaciones circularon entre un grupo reducido de profesionales, siendo limitada su difusión e incidiendo escasamente en la visión que históricamente se tuvo de Sevilla.

El grupo de representaciones que ahora interesa es muy numeroso, siendo resultado de la fama e importancia que adquirió Sevilla a partir del siglo XVI, al convertirse en el principal puerto europeo del comercio y las relaciones con las Indias. Ello ocasionó el aumento de su población, debido a la afluencia de nacionales y extranjeros, atrayendo la atención de numerosos artistas, quienes realizaron un nutrido repertorio de representaciones de la ciudad, que sivvieron para difundir su imagen por toda 


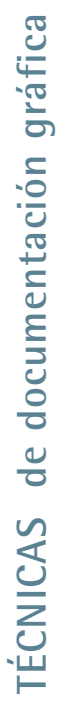

La toma de Sevilla por San Fernando. 1460.

Sello. Catedral. |4|1.

D. San Román y Cordina. La Giralda entre la paz y la fama. 1743-1789. Inscripción:

"Fábrica Martínez y Peña Hernáns en Sevilla".

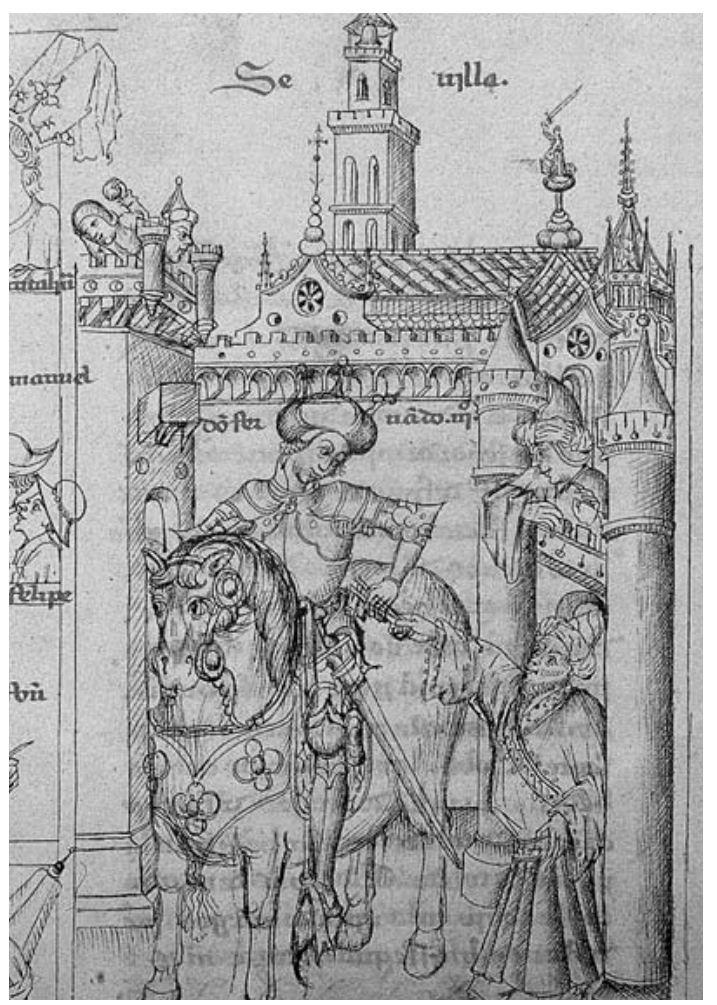

Europa durante la edad moderna '. El objeto de estas representaciones, además de la propia fisonomía de la ciudad en su conjunto, abarca una gran diversidad de temas, desde amplios parajes urbanos, como pueden ser la zona del puerto y del Arenal o la Alameda de Hércules, hasta edificios tan representativos como la Casa Lonja, el Alcázar o la Catedral. Junto a estas imágenes urbanas hay otras que dejan constancia de hechos históricos, políticos o socio-culturales-religiosos que tuvieron a la ciudad por escenario, caso de proclamaciones o visitas reales, celebraciones cívicas, festejos religiosos, o que simplemente muestran el devenir cotidiano de los sevillanos. Tales representaciones

no fueron concebidas con el fin de servir de testimonios históricos, valor con el que actualmente son muchas veces intepretadas, pues parten de otros objetivos. Esto hace que muchas de estas representaciones de Sevilla no plasmen fielmente la realidad, sino que sean recreaciones ilusorias sobre la ciudad o sus edificios, con las que se quiere resaltar elementos simbólicos o plasmar ciertos ideales religiosos o culturales. En este sentido, para analizar la evolución del urbanismo sevillano resultan de poca utilidad aquellas visiones en las que Sevilla aparece como la "ciudad ideal" o "la ciudad de Dios", en las que, a pesar de ser perfectamente reconocible se muestra irreal al cargase de valores y simbolismos profanos y religiosos, como aparece en la ilustración anónima de La toma de Sevilla por San Fernando, de la obra Genealogía de los Reyes de España de Alonso de Cartagena realizada hacia 1460, en la Cédula de Carlos V de 16 de julio de 1549 o en el cuadro de Zurbarán de la Inmaculada del Museo Diocesano de Sigüenza 2.

Del mismo modo, existen monumentos sevillanos, como puede ser la Giralda, posiblemente el edificio más representado a lo largo de la historia de la ciudad, que fueron dotados de unas connotaciones simbólicas, religiosas y profanas, que desvirtuaron su representación, sacándola del contexto en el que se encontraba. La torre catedralicia no sólo se convierte en el escudo del cabildo eclesiástico, sino que también, se va a constituir, a modo de sinécdoque, en el elemento símbolo de la propia ciudad de Sevilla. En ambos casos aparece aislada del conjunto catedralicio, acompañándose de las jarras de azucenas, al representar al cabildo catedralicio, o, en el segundo de los casos, entre las imágenes de los santos protectores y tutelares de la ciudad. Esta identificación entre torre y ciudad queda patente, desde el último cuarto del siglo $X V$, al ser utilizada por los plateros como marca para identificar la plata labrada en Sevilla o por los fabricantes de cintas de seda establecidos en la ciudad, para señalar sus productos.

Junto a estos ejemplos aislados, pero muy significativos de la "realidad irreal" que corresponde a algunas representaciones, resulta especialmente sugestivo centrarse en el caso de la catedral sevi-
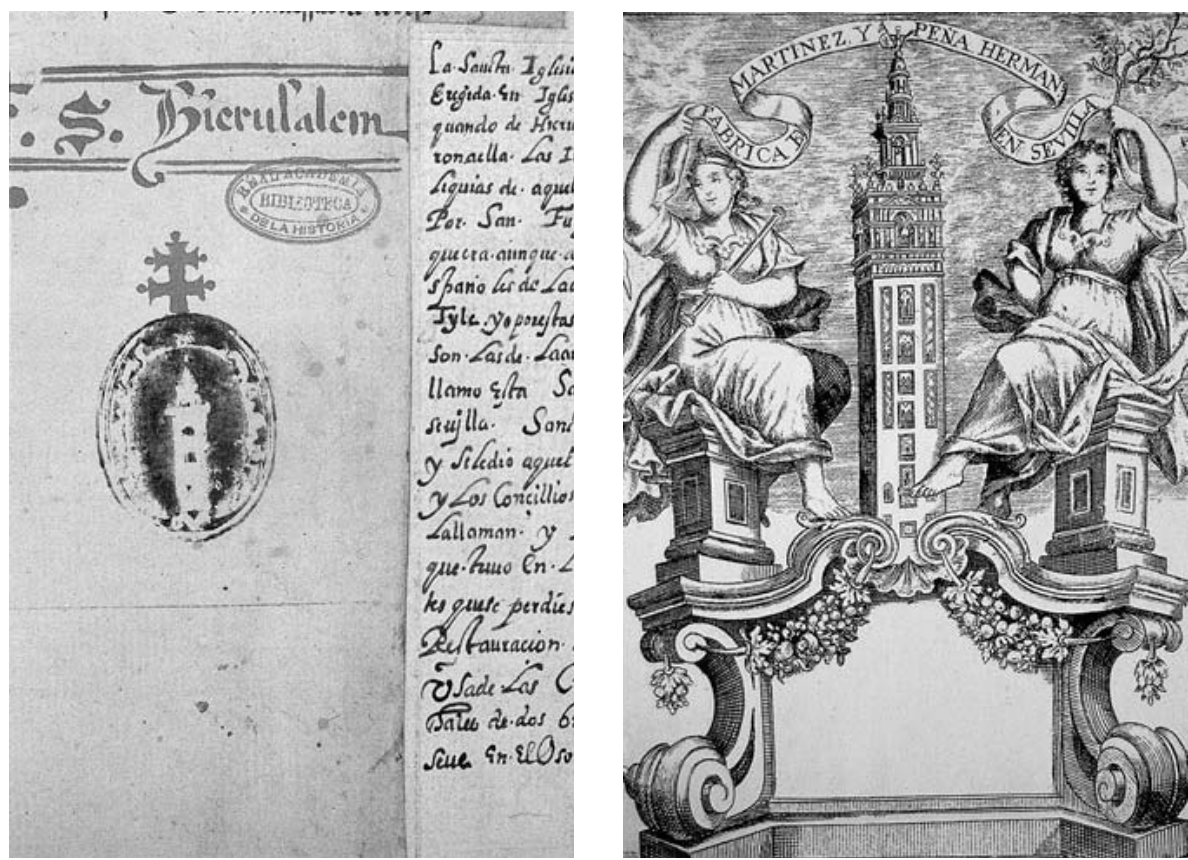
llana. De hecho, analizar la visión que de este singular monumento se ha ofrecido a los vecinos y extranjeros, entre los siglos XVI y XIX, constituye un sorprendente ejercicio. En principio, debe advertirse que los autores de tales imágenes del conjunto catedralicio se tomaron ciertas licencias, ofreciendo visiones completamente falsas o desvirtuadas, como las realizadas a mediados del ochocientos bajo el prisma del romanticismo. Sirva de ejemplo el lienzo de Jane Steele de la Procesión del Corpus, realizado en 1868, donde aparece la catedral, vista desde la actual calle Alemanes, con fábrica de ladrillo visto y basto alternando con hiladas de sillares de piedra, y con aspecto ruinoso. En otras ocasiones, estas visiones son reinterpretaciones de las vistas que del edificio circularon por Europa durante la edad moderna, producto, en muchas ocasiones, de artistas 
que jamás llegaron a visitar la ciudad. En ellas es notorio la pérdida de escalas con referencia al original, o incluso, la falta de perspectiva, originando que algunas de las construcciones catedralicias no coincidan con su emplazamiento original. En éste sentido, las vistas de la Catedral realizadas por Louis Meunier en 1668 se copiarán repetidamente hasta el siglo XVIII, siendo prueba de ello las estampas aparecidas en la obra Les delicies de l'Espagne et du Portugal, en 1707, y los grabados editados en París durante la misma centuria por D.Q. Huquier, cuya única novedad es el de estar coloreados ${ }^{3}$.

De las múltiples representaciones existentes sobre la Catedral, hay algunas realizadas con el fin de resaltar la importancia y magnificencia del templo sevillano, por lo que éste aparece completamente exento y sin ninguna referencia a su contexto urbano. Así aparece en los grabados realizados por Matías de Arteaga en 1672 para la obra de Torre Farfán, Fiestas de la Santa Iglesia Metropolitana y Patriarcal de Sevilla al nuevo culto del rey Señor San Fernando, o en los que ilustran la Descripción artística de la Catedral de Sevilla, obra publicada por Ceán Bermúdez en I804. Tanto en aquellas como en éstas, se muestran los diferentes frentes del edificio con gran definición en los detalles, lo que haría sospechar que se trata de imágenes reales del edificio. Sin embargo, las representaciones carecen de fidelidad, pues en ellas se han eliminado las edificaciones pertenecientes al cabildo y adosadas al propio templo, que pudieran entorpecer la visión o restarle belleza al conjunto. Tal libertad interpretativa es habitual entre los siglos XV al $X V I I I$, aún incluso en aquellas representaciones en las que el edificio se encuentra inmerso en el bullicio de la ciudad. Sirvan de ejemplo uno de los grabados que ilustró la obra de Daniel van Papenbroeck, Acta viatae S. Ferdinandi, publicado en Amberes en 1684, y realizado por Gaspar Buttats denominado La Giralda engalanada y la puerta sur de la Catedral o el de Matías de Arteaga de la Giralda engalanada, realizado para la obra de Torre Farfán, ya mencionada. De ellos, en el primero, han desaparecido las construcciones del Corral de los Olmos, representándose en el segundo, sólo una parte de las mismas, concretamente el edificio de mayor importancia, el utilizado como Sala de Rentas y Juzgado Eclesiástico.

Al analizar estas representaciones se advierte que esa libertad no es un hecho generalizado a todos los frentes del edificio, sino que depende de las dificultades que ofrezca el recoger los edificios adosados al templo, su importancia o su mayor o menor belleza. Así, será práctica habitual en los grabados realizados del frente meridional. Pedro Tortolero, en 1738, coloca este lado como telón de fondo del grabado de la Procesión del traslado del cuerpo de San Fernando a su nueva urna. En el mismo solo se ha representado el volumen renacentista de la Sacristía Mayor, la inconclusa Puerta del Príncipe, también denominada de San Cristóbal o de la Lonja, y el volumen correspondiente a la Capilla de la Antigua. El resto de la fachada, es decir el muro que encerraba las capillas de San Hermenegildo a la de San Laureano, aparece perfectamente definido, con sus contrafuertes y sin estar oculto por ninguna construcción. Esta representación es irreal, aunque refleja muy bien la idea que el propio cabildo catedralicio tenía sobre tal construcción, como se indica en un acuerdo capitular, aludiendo a "esta Santa Yglesia en su grandeza y primor de su fábrica (es) una Maravilla" añadiendo seguidamente que "no parece bien tenga este lunar en que todos reparan" 4. Ese lunar al que se refiere la cita y que no aparece representado en el grabado corresponde a una serie de casas, propiedad del templo, que no solo eran utilizadas como viviendas de alquiler, sino que también albergaban algunas oficinas de la Catedral, distribuidas en torno a un patinillo existente tras la capilla de Santa Ana. Así pues, el mencionado grabado de Tortolero a la hora de estudiar la imagen histórica de la ciudad podría haberse considerado como fidedigna, si no se conociera y tuviese en cuenta la documentación textual sobre las citadas dependencias y casas. Por el contrario, en el grabado realizado sobre el dibujo de Valdés Leal, titulado Puerta principal de la iglesia que sale a Gradas en frente del Triunfo para la obra de Torre Farfán, sobre las fiestas por la canonización de San Fernando, ya citada, aparece la decoración efímera que tuvo dicha portada y recoge dichas casas, convirtiéndose por ahora en la única imagen conocida de dichas construcciones. Así, entre los elementos integrantes de la decoración, aparece una representación de la misma fachada con las casas aludidas, aunque representadas ligeramente abocetadas. Estas casas fueron derribadas entre los años 1757 y 1758 , decidiéndose ese mismo año la construcción de un nuevo edificio de dos plantas, destinado a granero, que, proyectado por José de Herrera, venía a tener como fachada una reinterpretación del muro existente en el ángulo sureste, encerrando el conjunto de las Sacristías y la Sala Capitular. La obra de este edificio, que pasará por diferentes vicisitudes, no sería terminada hasta 1929 y con importantes reformas sobre el proyecto original ${ }^{5}$. No obstante, durante toda la segunda mitad del siglo XVIII, se eludirá su representación, siendo en 1804 cuando, tras haberse paralizado la edificación hacía cuatro años, se ofrezca la primera imagen de la misma. El grabado corresponde a la ilustración del ya citado libro de Ceán Bermúdez Descripción artística de la Catedral de Sevilla. Para este momento sólo se había construido la planta baja de las dos inicialmente proyectadas, sirviendo para albergar las oficinas del cabildo.

Sin embargo, las imágenes más difundidas de la catedral son las que corresponden a sus fachadas de poniente y la septentrional, ya que corresponden a unas de las principales arterias de la ciudad, denominada como Gradas, que sirven de escenario o telón de fondo de la vida cotidiana de los

1. Steele. Procesión del Corpus. 1868

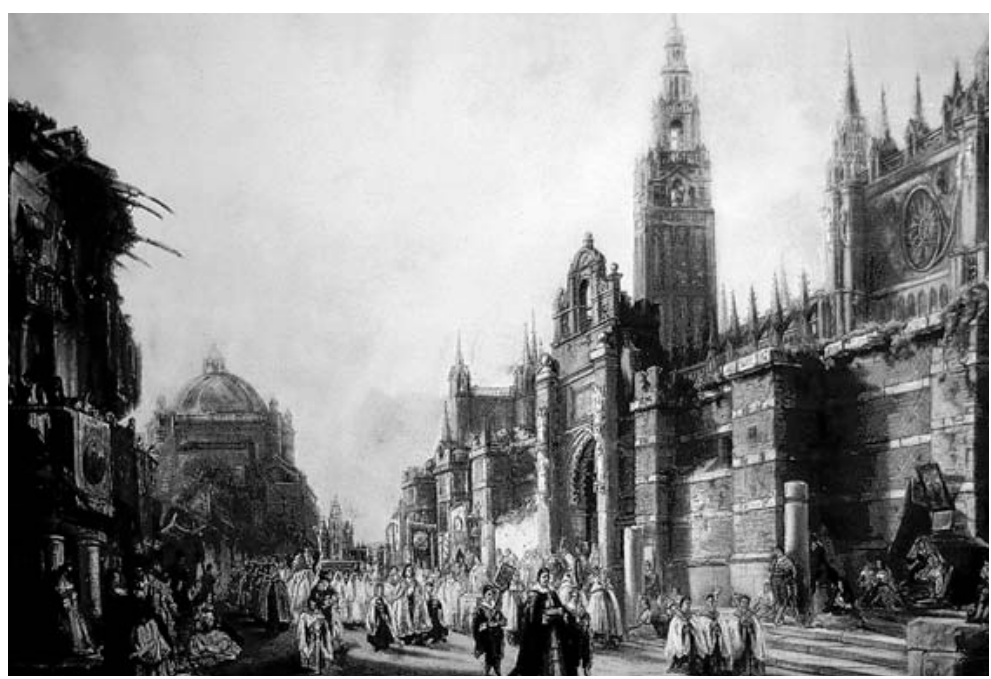




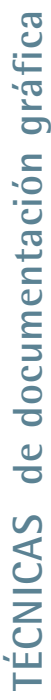

Catedral de Sevilla. Editado por D. Q. Huquier. Siglo XVIII.

P. Tortolero. Procesión del traslado del cuerpo de San Fernando. 1738.
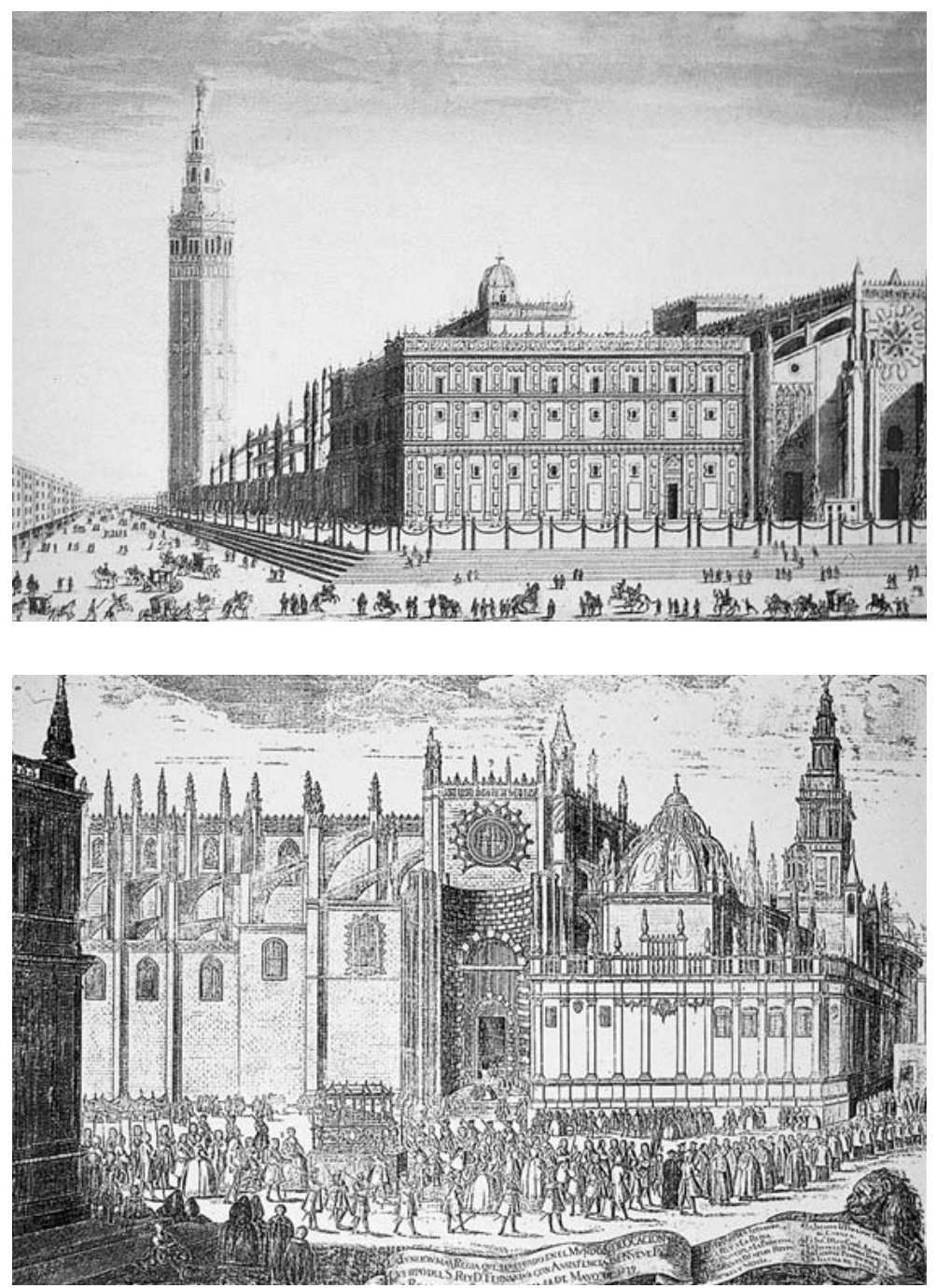

torre era una construcción bastante original, ya que en su planta baja existía un vano de ingreso entre ventanas y una cubierta en azotea que servía de balcón, cobijado por un gran arco. Sobre el mismo se disponía otro balcón corrido y áun otro más, en el cuerpo superior. La cubierta del conjunto era un tejado a dos aguas. La particularidad de la distribución de todos estos elementos hace pensar de que se trata de una edificación resultante de sucesivas transformaciones y acomodos a estructuras previas.

El arco de San Miguel es un elemento singular en la configuración urbanística del entorno de la catedral, teniendo cierta importancia en los días de fiestas, ya que durante las mismas, uno de sus balcones corridos era alquilado a los Almirantes de Castilla, con objeto de utilizarlo como palco para contemplar "el paso de las procesiones y otros desfiles solemnes", siendo los empleados de dicha institución los encargados de adornarlo y engalanarlo ${ }^{7}$. Esta cesión, en principio de carácter temporal, llegó a hacerse permanente, hasta tal punto que la torre más cercana al templo hispalense terminó por denominarse del Almirantazgo. Posiblemente, debido a estas circunstancias, al ser el elemento definitorio de este sector de las Gradas y a que podía interpretarse como parte del conjunto catedralicio, hizo que siempre estuviera presente en las representaciones de esta zona de la ciudad. Su derribo a principios de febrero de I 762 no fue óbice para que continuara representándose en las vistas que posteriormente se hicieron de este frente ${ }^{8}$. Así, después de casi cincuenta años de su desaparición, sigue apareciendo en estampas francesas de los primeros años del siglo XIX, o en las realizadas para la iluminación de la obra de Willian Jacob, Travels in the South of Spain in letters written, A.D. 1809 and I8I0, publicada en Londres en $|8| \mid$.

Por lo que respecta al sector norte de las Gradas, la actual calle Alemanes, siguió utilizándose como lugar de esparcimiento $y$, en ocasiones, al carecer Sevilla de una plaza mayor, por más que la plaza de San Francisco viniera a suplir muchas de sus funciones, se convertiría en escenario de muchas de las solemnidades religiosas y profanas ${ }^{9}$. En las representaciones que existen de este espacio, como el lienzo la Procesión de la Inmaculada, de 1662, en el que se recoge la fachada del Patio de los Naranjos oculta tras arquitecturas efímeras. De igual forma que en el lienzo denominado Carro del Agua, correspondiente a la serie de la Máscara de Domingo Martínez, se encuentra adornada con diferentes tapices. A pesar de la importancia del sector, las representaciones de este frente son escasas si se compara con el anterior, pues solo aparece en las ocasiones comentadas, o en representaciones generales de todo el sector de las Gradas. No será hasta el siglo XIX cuando se generalice la representación de este frente, aunque la imagen se limitará a elementos significativos como la Puerta del Perdón, que aparece aislada, como en el dibujo realizado por Pharamond Blanchard y que sirvió de ilustración a la obra de Justin Taylor Voyage pittoresque en Espagne, publicado en París en 1832, o sirviendo de telón de fondo de la vida cotidiana, tal y como recoge Joaquín Domínguez Bécquer en su cuadro de La Puerta del Perdón.

Frente a la escasez de representaciones de este sector, hay una mayor abundancia de imágenes del último tramo de las Gradas, el correspondiente a la prolongación de la calle Pla- 
centines. La presencia de la Giralda, símbolo de la ciudad, hacen de este sector el más representado a lo largo de la edad moderna. Sin duda, se debe a que este frente de la torre es el único exento, siendo la única visión completa que históricamente se ha tenido de la misma hasta el siglo XIX. No obstante, las licencias compositivas o la libertad de interpretación en las vistas de este sector llegan a su máxima consecuencia, pues si en algunos grabados se intenta representar fielmente la realidad urbanística de la zona, caso del grabado de Pedro Tortolero de La Giralda o de los lienzos de Domingo Martínez de El Carro del Fuego y la Carroza de la Alegría de la varias veces mencionada serie de la Máscara, en una gran mayoría desaparecerán ciertos elementos representativos del sector, como eran los Arcos Arzobispales y la Puerta de Palos que daba acceso al Corral de los Olmos. Este era un amplio recinto que ocupaba todo el frente oriental de la Catedral. A pesar de la importancia de las construcciones existentes en el mismo, ya que durante la edad media sirvió de sede a los cabildos civil y religioso, jamás va a ser representado. Posiblemente debido a su dificultad interpretativa y gráfica, este frente de la catedral no fue motivo de inspiración de ningún artista hasta que no desaparecieron las construcciones que lo ocultaban a fines del siglo XVIII. La única visión que se conserva del frente anterior a estas fechas, es la representación que a modo de maqueta de la Catedral, atribuida a Jorge Fernández Alemán, y realizada hacia I5 I I, se sitúa en el banco del retablo mayor del gran templo hispalense ${ }^{10}$. En la misma, abstrayendo las edificaciones del Corral de los Olmos se representa la cabecera de la Catedral con la Capilla Real, según el proyecto gótico. No será hasta la segunda mitad del siglo XVIII, cuando se vaya a proceder al derribo de las edificaciones del Corral de los Olmos y a remodelar este sector urbano, cuando se levanten varios planos de esta zona "I. Por ellos, se observa como el antiguo lienzo de la muralla almohade compartimentaba la actual plaza de la Virgen de los Reyes. Entre éste y la Catedral quedaba un reducido espacio conocido como Corral de los Olmos, para esas fechas ocupado por la Sala de Rentas y el Juzgado eclesiástico, las oficinas de las Contadurías de la Catedral, así como por almacenes y por el arca del agua. Se cerraba, en el Norte por la Puerta de Palos, junto a la Giralda, y, por el Sur, por la Puerta de Campanillas. Fuera del recinto quedaban los Arcos Arzobispales, que unían el palacio del que toman el nombre con la puerta de Palos, y un conjunto de pequeñas viviendas, que adosadas a la muralla almohade, se encontraban frente a la actual calle Mateos Gago, y, en el sur, el Arquillo de Santa Marta, que unía el Hospital del mismo nombre con el Corral. De todo este conjunto de edificaciones, los únicos elementos normalmente representados van a ser las dos puertas de acceso al Corral de los Olmos y los Arcos Arzobispales, hasta que se procedió al derribo de todas estas construcciones, entre los años 1756 y 179| 12. Así ocurre en los grabados realizados por Meunier titulados La Lonja y la Catedral, por Juan Fernández, sobre un dibujo de Tortolero, La Giralda, o en los lienzo de la Máscara de Domingo Martínez, del Carro de la Común Alegría y del Carro del Fuego.

Desaparecido el Corral, y tras ser colocadas las rejas en los dos atrios precedentes a las portadas orientales del templo, aparece una nueva perspectiva de la Catedral y de la Giralda que rápidamente serán captadas por grabadores y pin-
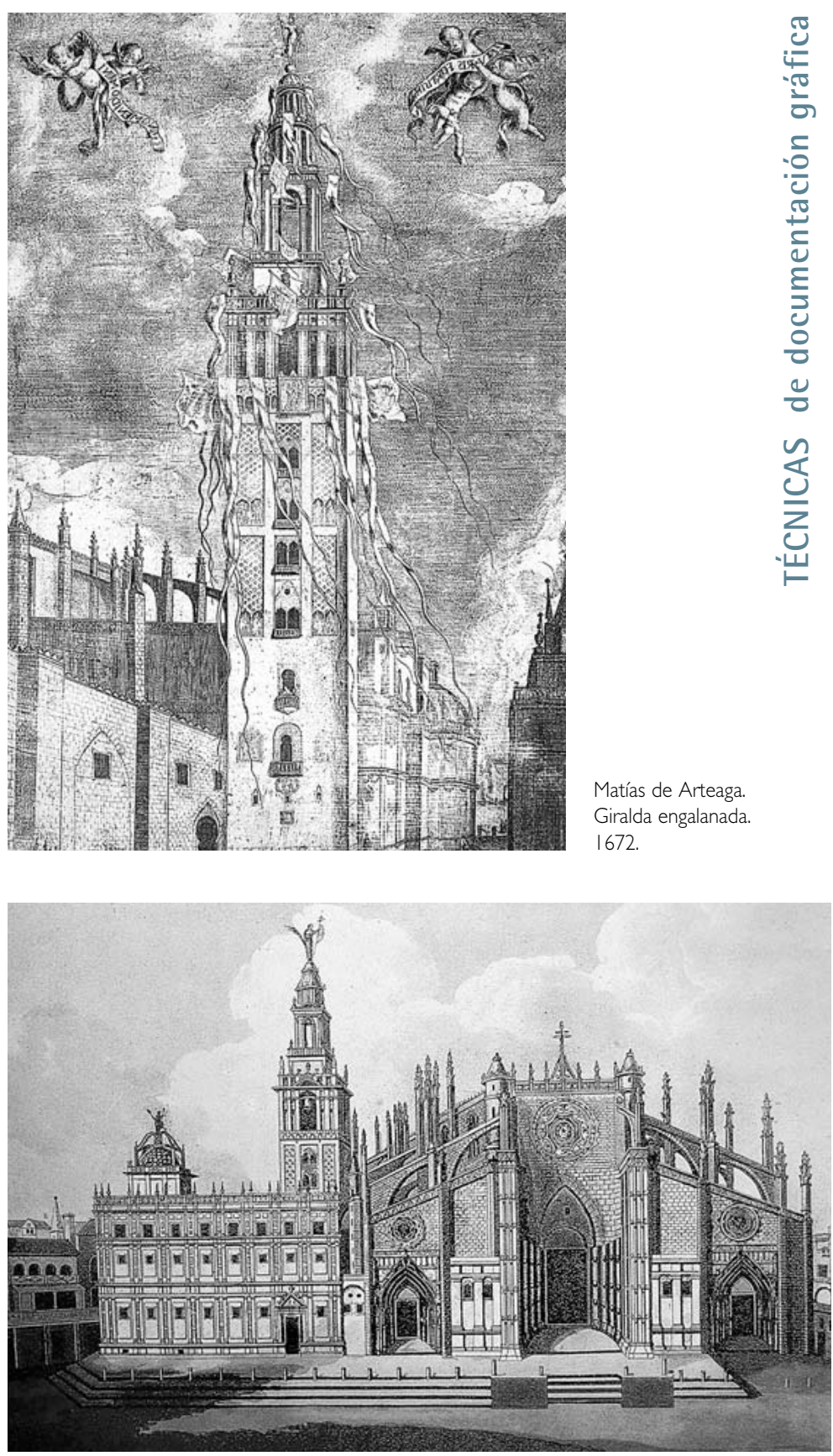

W. Jacob.

tores. No sólo se ofrecerá la visión del conjunto desde la Fachada de la Catedral. actual calle Matos Gago, aunque a veces modificada y falseada como en el cuadro del romántico Jenaro Pérez Villamil titulado La Giralda desde Borceguinería, sino que también serán elegidos los elementos del sector, para representarlos con gran fidelidad, como en el grabado que realizara Friedrich Eibner de la Puerta oriental de la Catedral, en I864, que apareció como ilustración en la obra de Mestchersky, Spanien: ansjchten nach aquarellzeichnunger.

En el siglo XIX, tras los derribos y modificaciones efectuadas en la centuria anterior, es cuando la Catedral ofrecerá una imagen muy parecida a la actual. No obstante, todavía algunas representaciones siguen ofreciendo visiones falseadas, como las anteriormente comentadas de Pérez Villamil o Jane Steele. Sin embargo, con el nacimiento de la fotografía, estas representaciones de "reali-
Matías de Arteaga. Giralda engalanada. 1672. 


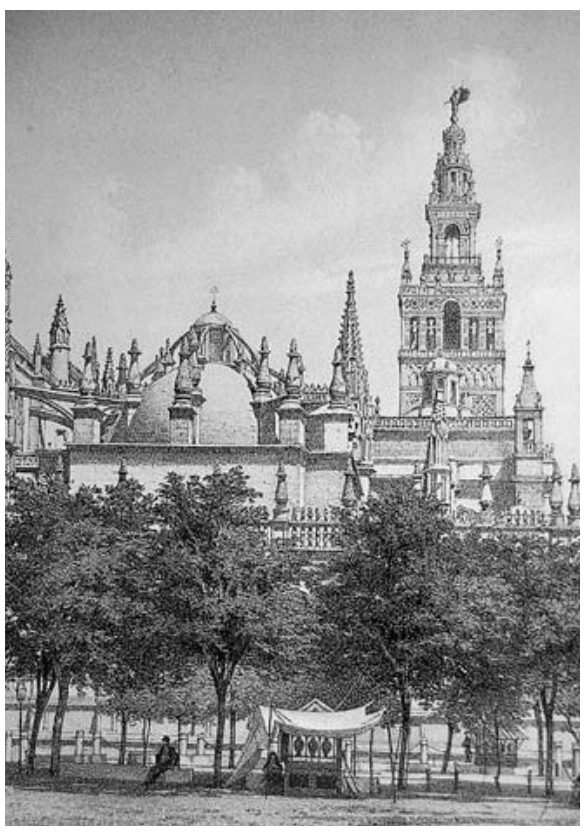

Vallejo. Litografía. 1863.

dad-irreal" que se habían ofrecido a lo largo de la edad moderna tienden a desaparecer. Y ello no sólo por la difusión de los logros de la nueva técnica, al reflejar fielmente la realidad, sino también por que éstos influirán decisivamente en las otras técnicas artísticas de represen- tación. Tanto grabadores como pintores, queriendo emular la imagen real que ofrecía la fotografía, se dejarán influir por la nueva técnica. Incluso se llegará mucho más lejos al no tomar a la Catedral como fuente directa de inspiración, sino al seguirse la visión que de ésta se había realizado a través del objetivo. Sirva de ejemplo la litografía realizada por Vallejo para la obra de Fernando CosGayón Crónica del viaje de Sus Majestades y Altezas Reales a Andalucía y Murcia en septiembre y octubre de 1862, Madrid, 1863, partiendo de una fotografía que realizara Charles Clifford.

La documentación gráfica histórica, al igual que la documentación fotográfica generada desde mediados de la centuria pasada, resultan un medio utilísimo para conocer la historia y la evolución de las ciudades y de los propios edificios, siendo imprescindible su utilización en cualquier proceso de investigación sobre los mismos. Sin embargo, algunos de los elementos, como se ha podido comprobar en estas páginas, pertenecientes al primer grupo, ofrecen una información valiosa, pero no siempre coincidente con la realidad del momento o de la época en el que fueron creados. Es por ello, que su utilización, durante un trabajo de investigación, debe realizarse con cierta cautela, ayudándose para su intepretación con la información aportada por otras fuentes documentales, que no sólo la aclararían, si no que también ayudarían a descubrir esa "realidad irreal" que, en determinadas ocasiones, puede aparecer.
I. Las imágenes que analizaremos en este trabajo pueden encontrarse en el repertorio iconográfico de la ciudad de Sevilla, formado por los volúmenes: CABRA LAREDO, Ma . Dolores y SANTIAGO PÁEZ, Elena Ma.: Iconografía de Sevilla: 1400-1650. Madrid, 1988. SERRERA, Juan Miguel, OLIVER CARLOS, Alberto y PORTÚS, Javier: Iconografía de Sevilla: 1650-1790. Madrid, 1989; CALVO SERRALLER, Francisco y PORTÚS, Javier: Iconografía de Sevilla: 1790-1868. Madrid, I991, y CALVO SERRALLER, Francisco, GOMEZ DE ARANDA, Lola y PORTÚS, Javier: Iconografía de Sevilla: 1869-1936. Sevilla, 1993

2. Consúltese, SERRERA, Juan Miguel: "Sevilla: imágenes de una ciudad". Iconografía de Sevilla: 1650-I790. Madrid, 1989. Págs. 37, 53.

3. PORTUS, Javier: "Catálogo". Iconografía de Sevilla: I650-I790. Madrid, 1989. Págs. 173, I81.

4. Archivo Catedral de Sevilla. Autos Capitulares. Año de 17|6. Fol. 16 vto.

5. Sobre el derribo de estas casas, así como la construcción del granero del cabildo y el edificio del ángulo suroeste de la Catedral, consúltese, HERNÁNDEZ NÚÑEZ, Juan Carlos: "El granero del Cabildo Hispalense. Historia y edificación." Archivo Hispalense, $n^{\circ}$. 217. 1988. Págs. 223-235. Del mismo autor, "La construcción de las dependencias catedralicias en el ángulo suroeste y su repercusión en el urbanismo sevillano". Archivo Hispalense, n. 233. 1993.Págs. 121-142.

6. MONTOTO, Santiago: Esquinas y conventos de Sevilla. Sevilla. 1963. Pág. 18
7. MONTOTO, Santiago: Ob. Cit. Págs. 7|-72.

8. Consúltese, HERNÁNDEZ NúÑEZ, Juan Carlos: "Noticias sobre el Arco de San Miguel durante el siglo XVIII". Laboratorio de Arte. n. 6. 1993. Págs. 179-188.

9. Véase, ÁlVAREZ, Lino, COLLANTES DE TERÁN, Antonio y ZOIDO, Florencio: "Plazas, "plaza mayor" y espacios de sociabilidad en la Sevilla intramuros". "Plaza" et sociabilité en Europe et Amerique Latine. París, 1982. Págs. 90-95.

10. MORÓN DE CASTRO, Ma. Fernanda: "Análisis histórico estilístiCO". El retablo mayor de la Catedral de Sevilla. Sevilla, I981. Págs. |40-|4|.

II. Dichos planos fueron dados a conocer por FALCÓN MÁRQUEZ, Teodoro: "Planos urbanísticos del Corral de los Olmos y su entorno". Homenaje al Dr. Muro Orejón. Vol. I. Sevilla, 1979. Págs. 247-256. Basándose en éstos y en la documentación gráfica de la zona, así como en diversas fuentes documentales, se hizo un curioso estudio-descriptivo de la evolución del Corral y su edificaciones, aunque resulta incompleto, existiendo importantes lagunas y algún que otro error motivado por el tipo de fuentes utilizadas: GRANERO MARTíN, Francisco: El Corral de los Olmos: antiguos cabildos secular y eclesiástico de la ciudad: Sevilla: sus orígenes, funciones, compilación de transformaciones y demolición. Sevilla. 1992.

12. Sobre la demolición del Corral de los Olmos, véase: HERNÁNDEZ NÚÑEZ, Juan Carlos: "Transformaciones urbanas en Sevilla durante el siglo XVIII: el derribo del Corral de los Olmos". Archivo Hispalense, n 232. 1993. Págs.89- 107. 